\title{
Multiple solutions for polyharmonic equations with potential vanishing at infinity
}

\author{
Kisoeb Park ${ }^{1}$, Jae-Myoung $\mathrm{Kim}^{2}$, and Jongrak Lee ${ }^{3}$ \\ ${ }^{1}$ Incheon National University \\ ${ }^{2}$ Andong National University \\ ${ }^{3}$ Jeju National University
}

May 5, 2020

\begin{abstract}
We are concerned with the following polyharmonic equation: \begin } \{ \text { equation* } \} \backslash \text { Delta_p } { } ^ { \wedge } \mathrm { L } \mathrm { u } + \mathrm { V } ( \mathrm { x } ) | \mathrm { u } | ^ { \wedge } \{ \mathrm { p } - 2 \} \mathrm { u } = \mathrm { K } ( \mathrm { x } ) \mathrm { f } ( \mathrm { x } , \mathrm { u } ) and $\mathrm{u}>0$ in $\backslash \mathrm{Bbb} \mathrm{R}^{\wedge} \mathrm{N}, \backslash$ end $\{$ equation*\} where $\$ 1<\mathrm{p}<\backslash$ infty $\$, \$ \mathrm{~N}>\mathrm{Lp} \$, \$ \mathrm{~L}=1,2, \backslash$ cdots $\$$ and the potential functions $\$ \mathrm{~V}$, $\mathrm{K}: \backslash \mathrm{Bbb} \mathrm{R}^{\wedge}\{\mathrm{N}\} \backslash$ to $(0, \backslash$ infty $) \$$ are continuous. We study the existence and multiplicity of nontrivial positive weak solutions for the problem above via mountain pass theorem and fountain theorem.
\end{abstract}

\section{Hosted file}

PKLB_polyharmonic_final_2020.pdf available at https://authorea.com/users/302433/articles/ 432520-multiple-solutions-for-polyharmonic-equations-with-potential-vanishing-atinfinity 